\title{
HIAPER: THE NEXT GENERATION NSF/NCAR RESEARCH AIRCRAFT
}

By KRISTA K. LAURSEN, DaVID P. JORGensen, GUY P. BRASSEUR, SUSAN L. USTIN, AND JAMES R. HUNING
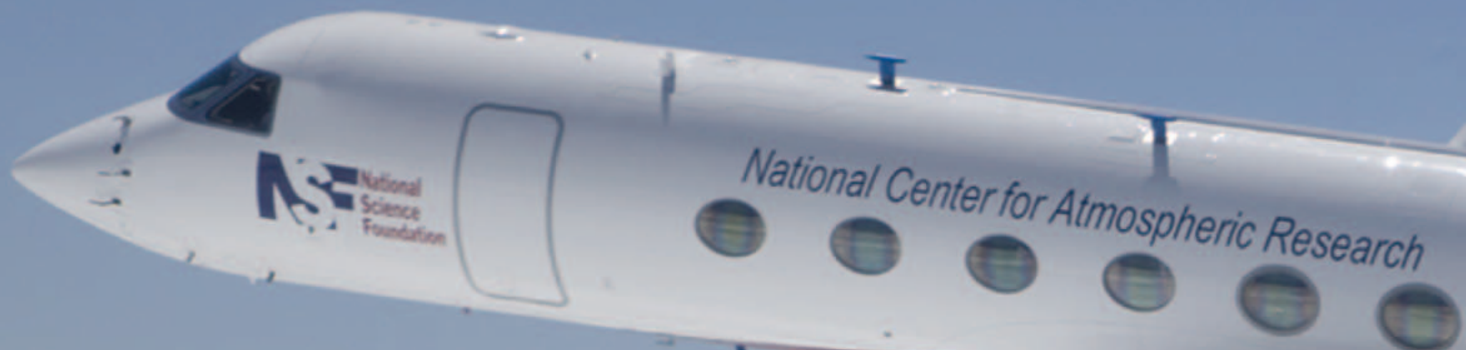

A recently developed research aircraft will usher in a new era of environmental research opportunities for investigators wanting to study the Earth's atmosphere and surface on a worldwide basis.
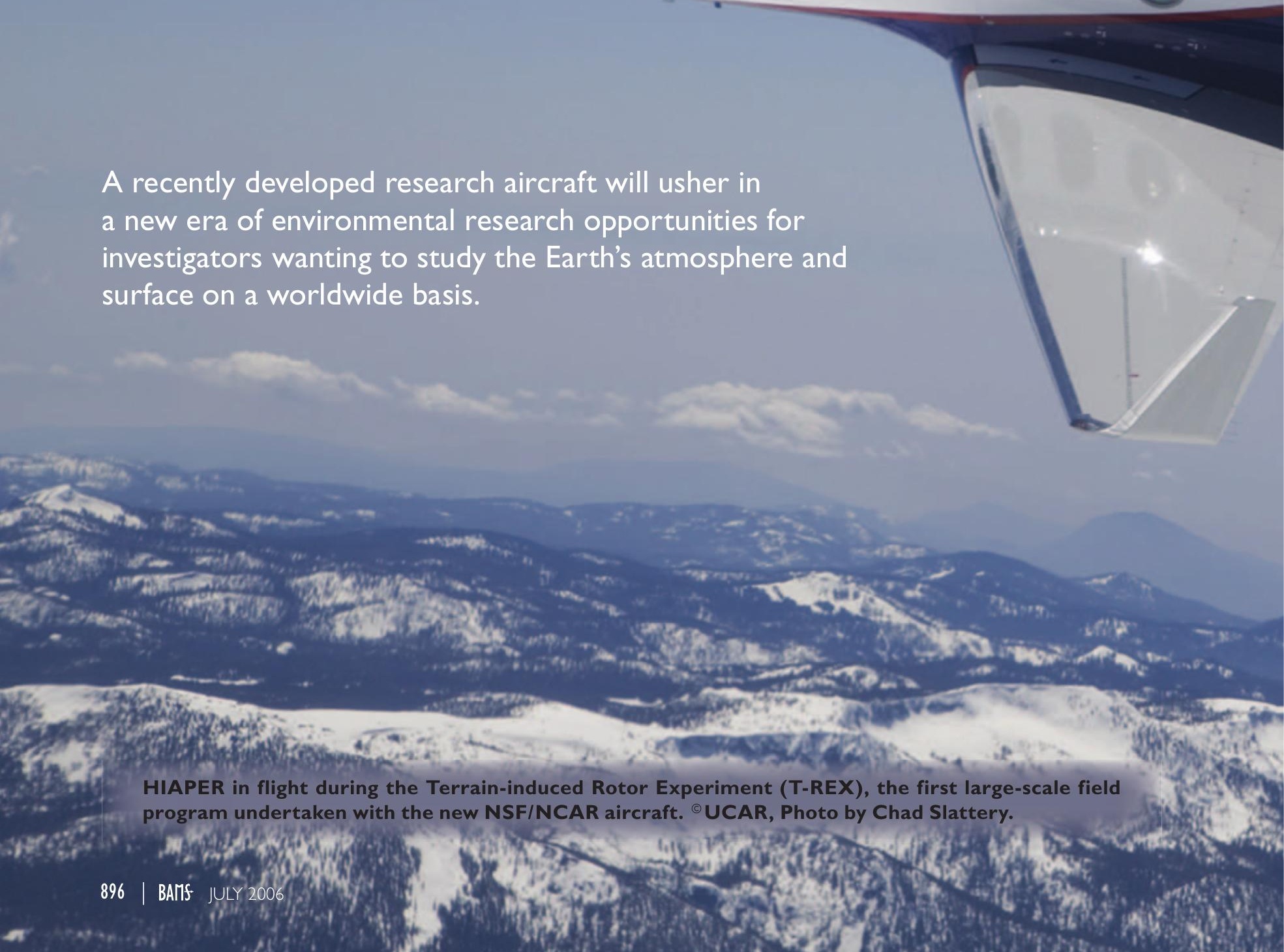


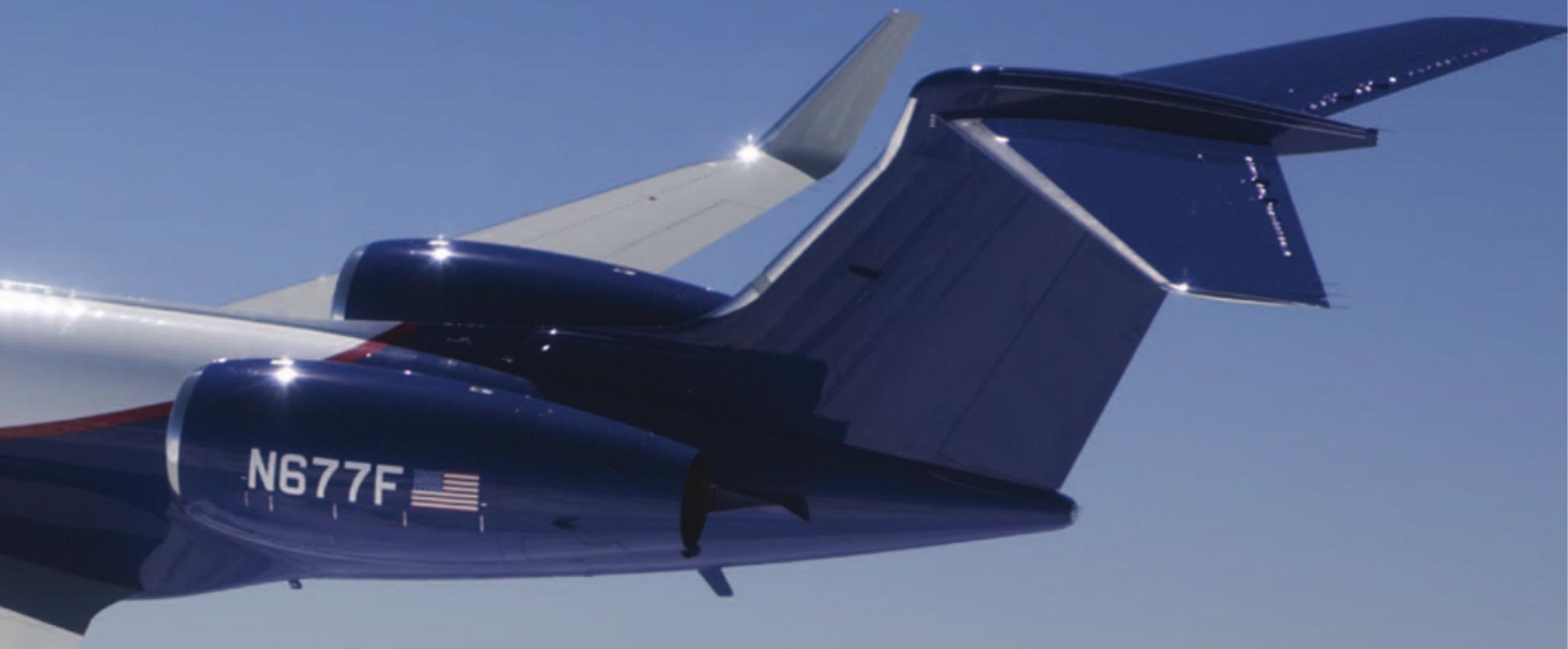

n late 2005, a new research platform began support of environmental research. The High-Performance Instrumented Airborne Platform for Environmental Research (HIAPER) represents the culmination of over two decades of effort by university investigators and personnel at the National Science Foundation (NSF) and the National Center for Atmospheric Research (NCAR) to obtain the funding needed for the aircraft acquisition,

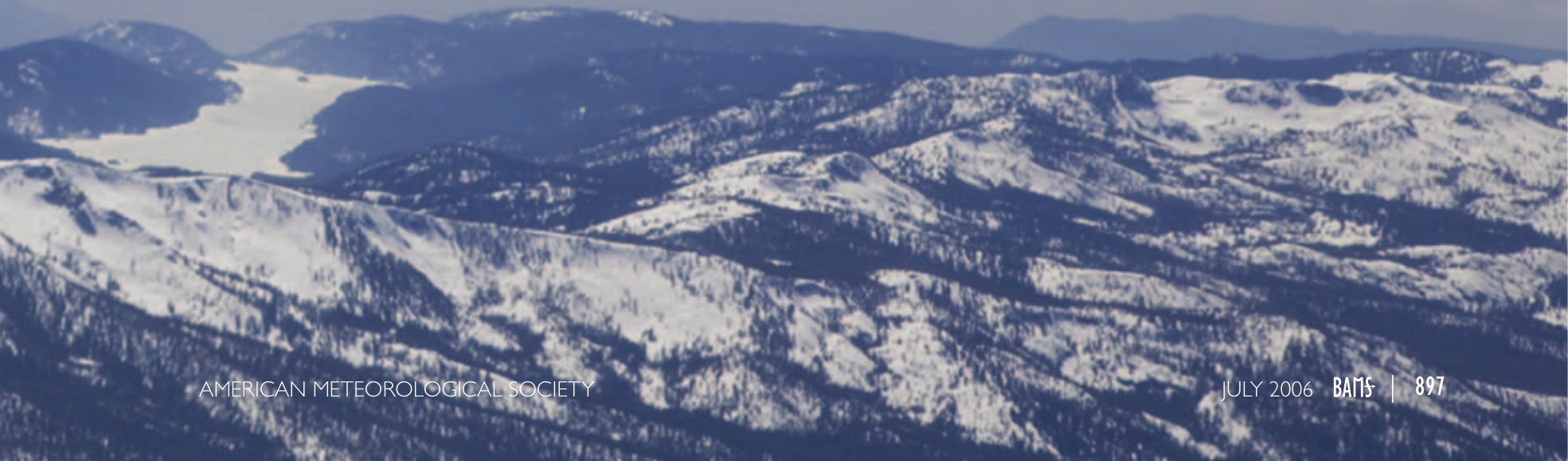




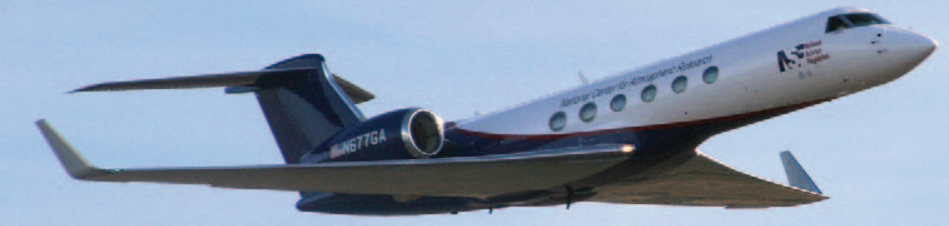

FIG. I. HIAPER, a modified Gulfstream V business jet. ${ }^{\odot}$ UCAR, Photo by Carlye Calvin.

and to work with members of the scientific community to define the performance attributes and desired configuration of this new, stateof-the-art platform. It is the most sophisticated aircraft ever operated by NCAR, and its combination of long-range $(\sim 11,000 \mathrm{~km})$, high-altitude $(\sim 15 \mathrm{~km})$, and endurance $(\sim 10 \mathrm{~h})$ performance characteristics will enable investigators to conduct vital new research studies in critical regions of the earth's atmosphere and over remote sections of the planet's surface.

Beginning in the 1980s, NSF, NCAR, and communitybased science planning groups

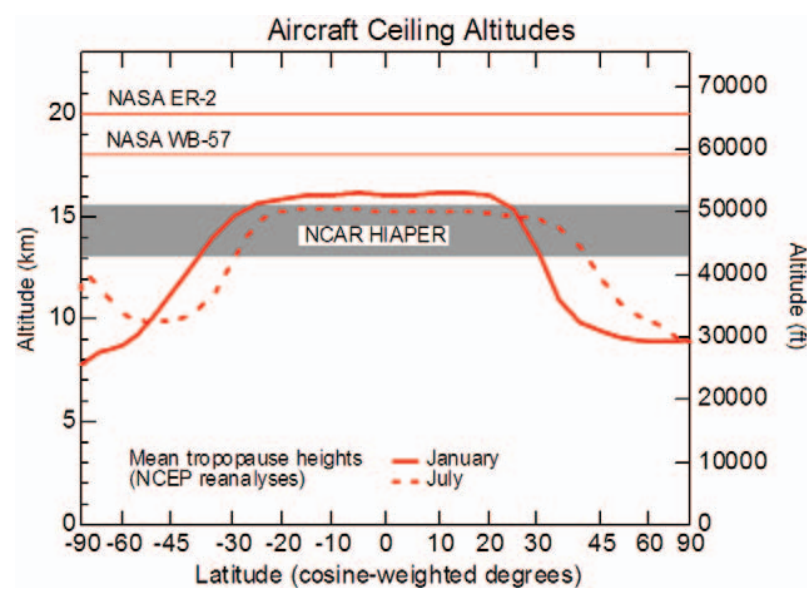

FIG. 2. Nominal ceiling altitudes of the HIAPER and NASA high-altitude aircraft operating for long distances with substantial payloads. The ceiling altitude range for HIAPER reflects payload weight. Note that the horizontal axis is cosine weighted to yield a display of equal areas on the globe. Data courtesy of W. Randel and F. Wu (NCAR). Figure courtesy of David Fahey (NOAA).

AFFILIATIONS: LAURSEN-National Center for Atmospheric Research, Boulder, Colorado*; JORGENSEN-NOAA/National Severe Storms Laboratory, Norman, Oklahoma; BRASSEUR-Max Planck Institute for Meteorology, Hamburg, Germany, and National Center for Atmospheric Research, Boulder, Colorado; Ustin-University of California, Davis, Davis, California; HUNING-National Science Foundation, Arlington, Virginia.

*The National Center for Atmospheric Research is sponsored by the $\mathrm{Na}$ tional Science Foundation. repeatedly expressed a strong scientific need for a midsized jet aircraft to be used to conduct research into environmental problems that could not be efficiently studied using other platforms and instruments (Hildebrand and McCarthy 1983; Johnson and Cooper 1989; Cooper et al. 1989). In the late 1990s, the opportunity to seek the necessary funds to acquire a midsized jet presented itself in the form of the Major Research Equipment and Facilities Construction (MREFC) program at NSF. In 1998, NCAR submitted a proposal for HIAPER to the National Science Board (NSB), which approved the continuation of the planning effort. The conduct of a community survey and workshop at NCAR in 1999 led to the definition of the following priorities for the new research jet (in descending order of importance): altitude, endurance, range, payload, and floor space. These results drew a clear picture of the need for a midsized jet that would truly allow investigators to go "higher, farther, faster" in their studies of the global environment.

CORRESPONDING AUTHOR: Krista K. Laursen, National Center for Atmospheric Research, P.O. Box 3000, Boulder, CO 80307 E-mail: krista@ucar.edu

The abstract for this article can be found in this issue, following the table of contents.

DOI:10.II75/BAMS-87-7-896

In final form I5 July 2005

C2006 American Meteorological Society 
During 2000 and 2001, initial funds were awarded to HIAPER from the MREFC program to begin the acquisition process. The appropriation of additional funds in fiscal year 2002 by Congress cleared the way for the University Corporation for Atmospheric Research (UCAR) to complete the proposal solicitation, review, and award process for the new aircraft, and in December 2001, UCAR awarded a contract to Gulfstream Aerospace Corporation for production of the basic aircraft, a Gulfstream V (GV) business jet. After rolling off of the Gulfstream production line in Savannah, Georgia, in June 2002, the green aircraft (so-called because of the color of the fuselage prior to final painting) was transferred to Greenville, South Carolina, for modification by Lockheed Martin. The outfitting of the GV with the requisite modifications (optical view ports, aperture plates, fuselage hard points, forward fuselage pads, and under-wing hard points) and a research power system was completed in the fall of 2004, and the aircraft was then returned to Savannah for interior and exterior completion by the Garrett Aviation Consulting Group and the Savannah Air Center. The total price tag for the HIAPER program was $\$ 81.5$ million, including $\$ 10$ million for the development and integration of critical infrastructure systems [e.g., a data acquisition system and data display software, satellite communication (SATCOM) systems, etc.], and $\$ 12.5$ million for the development of new instrumentation. For more information regarding the HIAPER project in general, visit the HIAPER Web site at www.hiaper.ucar.edu. This article focuses on what this considerable investment of financial and personnel resources has yielded in terms of a state-of-the-art research aircraft (Fig. 1).

AIRCRAFT PERFORMANCE CHARACTERISTICS. With the ability to carry payloads as high as $15,500 \mathrm{~m}(51,000 \mathrm{ft})$ and range capabilities exceeding $11,100 \mathrm{~km}$, the GV will make possible studies of the upper troposphere, the tropopause region in all but the deep Tropics, and the lower stratosphere at midlatitudes. While other platforms in the U.S. research aviation fleet [e.g. the National Aeronautics and Space Administration (NASA) DC-8, WB-57F, and ER-2s and the National Oceanic and Atmospheric Administration (NOAA) Gulfstream IV] provide some research capabilities in these regions, none of these aircraft possess the combination of altitude, range, and payload possibilities afforded by HIAPER (Figs. 2 and 3; Table 1). Figure 4 shows a comparison of performance attributes of HIAPER and the NSF/NCAR C-130. For the maximum payload and maximum fuel scenarios depicted, the altitude and range capabilities of the GV are roughly double those of the C-130. (It should be noted, however, that the maximum payload that can be flown on the C-130 is nearly 3 times that of the GV.) It must be acknowledged that the upper-

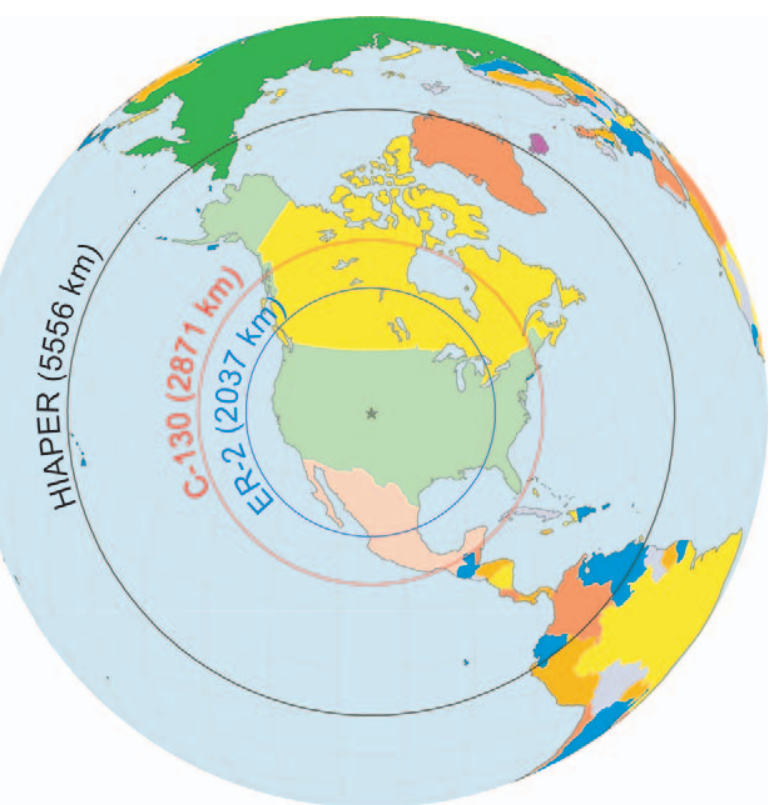

Fig. 3. A comparison of the maximum ranges for HIAPER (black circle), the NSF/NCAR C-130 (red circle), and the NASA ER-2 (blue circle). The circles shown represent the maximum distance to which each aircraft can fly from a base at Jefferson County Airport in Broomfield, CO (represented by the star), and return to the same base. The ranges shown correspond to flight of each aircraft at optimum altitude for ferry $(12,500 \mathrm{~m}$ for HIAPER, $6100 \mathrm{~m}$ for the C-130, and 19,800 $\mathrm{m}$ for the ER-2) and with the maximum possible payload deployed on each aircraft.

\begin{tabular}{|c|c|}
\hline Maximum operating altitude & $15,500 \mathrm{~m}(51,000 \mathrm{ft})$ \\
\hline Maximum scientific payload & $3540 \mathrm{~kg}(7800 \mathrm{lb})$ \\
\hline Maximum scientific payload at maximum range $(11,100 \mathrm{~km})$ & $2490 \mathrm{~kg}(5500 \mathrm{lb})$ \\
\hline $\begin{array}{l}\text { Loiter (research) time at } 10,668 \mathrm{~m}(35,000 \mathrm{ft}) \text { with payload } \\
\text { of } 2990 \mathrm{~kg}(6600 \mathrm{lb})\end{array}$ & $13.4 \mathrm{~h}$ \\
\hline $\begin{array}{l}\text { Loiter }(\text { research }) \text { time at } 15,200 \mathrm{~m}(50,000 \mathrm{ft}) \text { and } 15,500 \mathrm{~m} \\
(51,000 \mathrm{ft}) \text { with payload of } 1180 \mathrm{~kg}(2600 \mathrm{lb})\end{array}$ & $3.1 \mathrm{~h}$ \\
\hline True airspeed at $9140 \mathrm{~m}(30,000 \mathrm{ft})$ & $195 \mathrm{~m} \mathrm{~s}^{-1}$ \\
\hline True airspeed at $12,200 \mathrm{~m}(40,000 \mathrm{ft})$ and above & $227 \mathrm{~m} \mathrm{~s}^{-1}$ \\
\hline
\end{tabular}




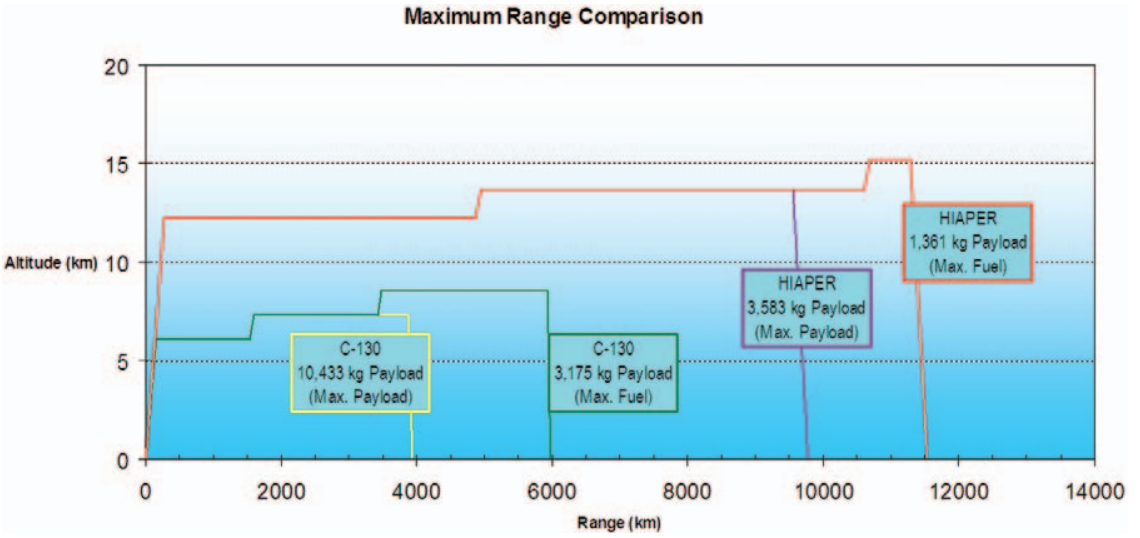

Fig. 4. Capabilities of HIAPER as compared to the NSF/NCAR C-I30. Data shown for the performance of HIAPER correspond to 15 drag counts applied to the GV airframe and the inclusion of a $1490 \mathrm{~kg}(3280 \mathrm{lb})$ fuel reserve [sufficient for landing at an alternate site $370 \mathrm{~km}$ away with $680 \mathrm{~kg}(1500 \mathrm{lb})$ of fuel in reserve]. Figure courtesy of Mark Lord (NCAR).
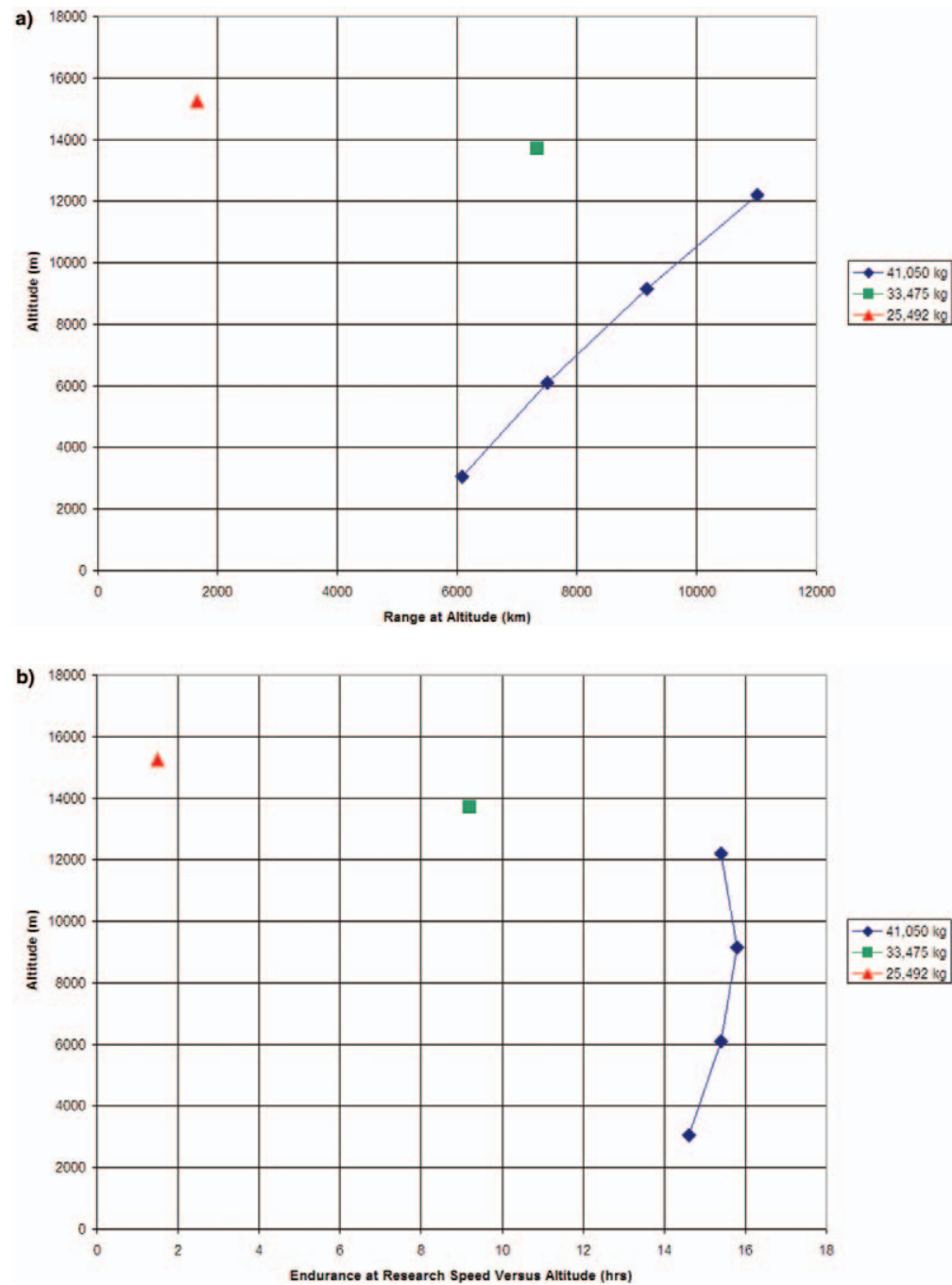

altitude limit of HIAPER will not permit scientists to collect in situ data in some of the higher regions of the tropical tropopause (see Fig. 2). However, modifications made to the GV (specifically, the installation of large-diameter zenith view ports) will make it possible for investigators to deploy uplooking remote sensing instruments on the aircraft for the purpose of studying these upper-atmospheric regions.

The successful execution of various mission profiles and research objectives with the GV will require the recognition of, and adherence to, specific aircraft performance attributes on the part of the scientific community. For example, the GV will be capable of deploying payloads weighing up to almost $3630 \mathrm{~kg}$ $(8000 \mathrm{lb})$. However, it will not be possible to carry the largest possible payload to the maximum range or altitude of the aircraft. Specifically, for each $45 \mathrm{~kg}$ of payload weight, approximately $39 \mathrm{~km}$ of range and roughly $9 \mathrm{~m}$ of altitude must be subtracted. Similarly, drag counts (i.e., the penalty resulting from

Fig. 5. (a) Range versus altitude and (b) endurance versus altitude capabilities of HIAPER for three different aircraft takeoff weights. Blue symbols correspond to a takeoff weight of $41,050 \mathrm{~kg}$ $(90,500 \mathrm{lb}$; maximum takeoff weight of the GV), the green symbol a takeoff weight of $33,475 \mathrm{~kg}(73,800 \mathrm{lb})$, and the red symbol a takeoff weight of 25,492 kg (56,200 lb). For all cases shown, the takeoff weight includes a research payload of $1590 \mathrm{~kg}(3500 \mathrm{lb})$ and $726 \mathrm{~kg}$ $(1600 \mathrm{lb})$ of fuel reserves. Additionally, the data shown are for scenarios in which 15 drag counts are applied to the GV airframe and the aircraft takes off and flies directly to the altitude value shown in the graphs. 
aerodynamic forces on the aircraft) applied to the GV airframe (in the form of wing pods, inlets, or other externally mounted equipment) result in range and altitude degradation for the aircraft: 1 drag count (roughly equivalent to one small wing pod) applied to the airframe results in a loss of approximately $39 \mathrm{~km}$ in range and approximately $20 \mathrm{~m}$ in altitude.

Such constraints need not, however, lead to significant sacrifices in capability. Indeed, within the payload envelope that can be supported by HIAPER, investigators will be able to perform long-range missions in critical levels of the atmosphere and over significant portions of the Earth's surface. As an example, for a research payload of slightly over $1580 \mathrm{~kg}$ (roughly $3480 \mathrm{lb}$ ) and an associated drag count of 15 , it will be possible to fly for over $14 \mathrm{~h}$ for a range exceeding $6000 \mathrm{~km}$ at altitudes of between approximately 3000 and 12,000 m (Fig. 5). Payload configuration and GV flight planning will need to be carefully integrated in order for investigators to achieve their research objectives with HIAPER. NCAR personnel intend to work closely with scientists throughout the planning and execution phases of
GV projects in order to ensure that optimal payloads and mission profiles are designed that will together yield the greatest possibility for mission success.

\section{BUILDING HIAPER FROM THE GROUND UP: FROM GREEN AIRCRAFT TO RE-} SEARCH-READY PLATFORM. Airframe modifications. Modifications made to prepare the HIAPER airframe for research (Table 2) are intended to provide environmental scientists with a number of possibilities for the deployment of instrumentation on the aircraft (Fig. 6). Wing pods and other sensors (e.g., cloud physics or aerosol probes) can be mounted on three hard points under each wing. The three large-diameter $(52.1 \mathrm{~cm}$, or $20.5 \mathrm{in})$ optical view ports (one up- and two downlooking) provide investigators with unprecedented opportunities for the deployment of large-aperture viewing and remote sensing equipment. Numerous aperture plates and fuselage hard points located on the upper and lower fuselage have been designed for the installation of inlets, antennas, and other small instruments per the requirements of individual projects.

\begin{tabular}{|c|c|c|c|}
\hline $\begin{array}{l}\text { Modification (quantity } \\
\text { given in parentheses) }\end{array}$ & Location & General description & Intended usage \\
\hline Aperture pads/plates (8) & $\begin{array}{l}\text { Top (6) and bottom (2) of } \\
\text { fuselage }\end{array}$ & $\begin{array}{l}\text { Each plate/pad } 25.4 \mathrm{~cm}(10 \mathrm{in}) \\
\text { long by } 17.8 \mathrm{~cm}(7 \mathrm{in}) \text { wide }\end{array}$ & $\begin{array}{l}\text { Sampling inlets and small } \\
\text { sensors }\end{array}$ \\
\hline Fuselage mounts (8) & $\begin{array}{l}\text { Top (4) and bottom (4) of } \\
\text { fuselage; } 6 \text { of the mounts } \\
\text { installed at various locations on } \\
\text { aircraft centerline, and I each } \\
\text { of the upper and lower mounts } \\
\text { installed off of centerline }\end{array}$ & $\begin{array}{l}\text { Each mount } 10.8 \mathrm{~cm}(4.25 \mathrm{in}) \\
\text { long by } 7.6 \mathrm{~cm}(3 \mathrm{in}) \text { wide with a } \\
4.4-\mathrm{cm}(1.75 \mathrm{in}) \text { diameter hole in } \\
\text { the center }\end{array}$ & $\begin{array}{l}\text { Small sampling inlets, } \\
\text { antennas, bulkhead feed- } \\
\text { through connectors, or lugs } \\
\text { for securing external fairings }\end{array}$ \\
\hline Forward fuselage pads (6) & $\begin{array}{l}2 \text { beneath GV windscreen and } \\
2 \text { on either side of aircraft } \\
\text { radome }\end{array}$ & $\begin{array}{l}\text { Each pad a mounting plate } \\
\text { I2.I cm ( } 4.75 \mathrm{in}) \text { by } 11.4 \mathrm{~cm} \\
(4.5 \mathrm{in}) \text { with a } 5.1-\mathrm{cm}(2 \mathrm{in}) \\
\text { diameter hole in the center of } \\
\text { the pad to allow for mounting/ } \\
\text { internal clearance of a cylinder } \\
5.1 \mathrm{~cm}(2 \mathrm{in}) \text { in diameter and } \\
10.2 \mathrm{~cm}(4 \mathrm{in}) \text { in length }\end{array}$ & $\begin{array}{l}\text { NCAR personnel using pads } \\
\text { for the installation of state } \\
\text { parameter (e.g., temperature } \\
\text { and dewpoint) sensors }\end{array}$ \\
\hline Optical view ports (3) & $\begin{array}{l}\text { Top (I) and bottom ( } 2) \text { of } \\
\text { fuselage on aircraft centerline; } \\
\text { forward-most downlooking } \\
\text { and uplooking ports coaligned } \\
\text { vertically and also overlap with } \\
\text { forward-most window on each } \\
\text { side of the aircraft }\end{array}$ & $\begin{array}{l}\text { Each view port } 52.1 \mathrm{~cm}(20.5 \mathrm{in}) \\
\text { in diameter; aft down look- } \\
\text { ing port structure capable of } \\
\text { supporting load associated with } \\
\text { mounting of external equipment }\end{array}$ & $\begin{array}{l}\text { Remote sensing } \\
\text { instrumentation and } \\
\text { imaging devices }\end{array}$ \\
\hline Wing hard points (6) & Wing underside ( 3 each wing) & $\begin{array}{l}\text { Each hard point capable of sup- } \\
\text { porting a maximum static load } \\
\text { of } 680 \mathrm{~kg}(1500 \mathrm{lb})\end{array}$ & $\begin{array}{l}\text { Wing pods and other sensors } \\
\text { (cloud and aerosol probes, } \\
\text { etc.) }\end{array}$ \\
\hline
\end{tabular}


a)

b)

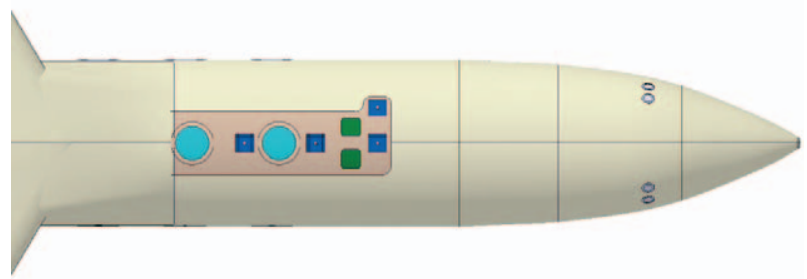

c)

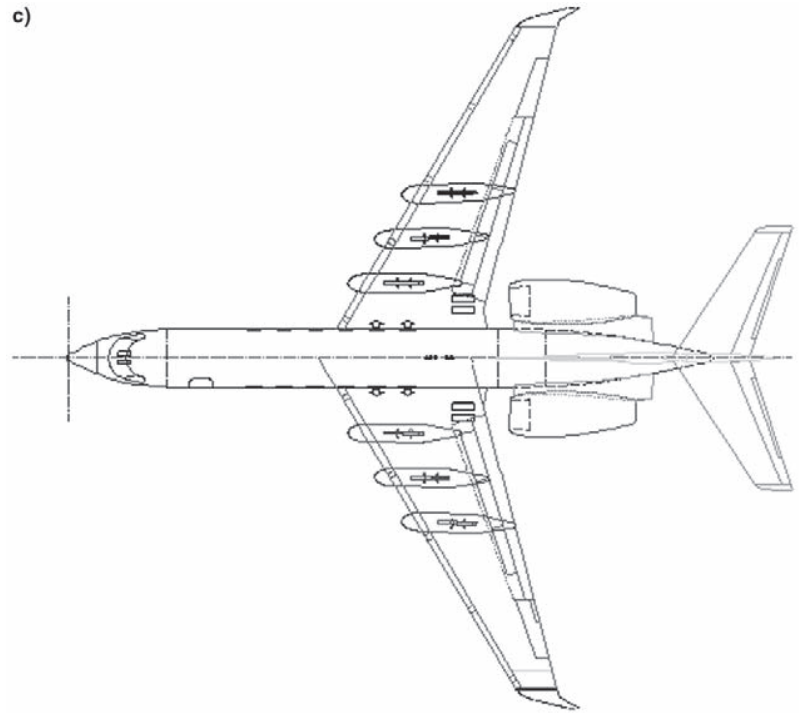

FIG. 6. Locations of modifications on the (a) upper and (b) lower fuselage and (c) underneath the wings of the GV. In views (a) and (b) of the fuselage, optical view ports are shown in light blue, aperture pads and plates in green and red, fuselage mounts in dark blue, and forward fuselage pads as light grey circles. In view (c), notional wing stores are shown mounted at each wing hard point. Drawings courtesy of Lockheed Martin [(a), (b)] and Gulfstream Aerospace Corporation [(c)].

tion. NCAR is, however, encouraging investigators to employ data digitization at the source instrument wherever possible so that the inherent noise immunity, error correction, and high-speed capabilities of digital networking can be fully exploited on the aircraft. Several networks are available throughout the GV to allow for separate data collection, display, and distribution functions.

Readers interested in obtaining more detailed information about the research configuration and system capabilities of the GV are encouraged to consult the NSF/NCAR GV Investigator's Handbook online at www.hiaper.ucar.edu/handbook.

Infrastructure systems. Following delivery of the modified GV to UCAR in March 2005, NCAR personnel assumed responsibility for the integration and testing of essential infrastructure systems on the aircraft. Brief overviews of critical systems that have been installed on HIAPER are provided below. (Further details about the HIAPER infrastructure systems are available online at www.hiaper.ucar.edu/specs.html.)

- Data acquisition system: The new GV data system relies on distributed data sampling via small modules located in the aircraft nose, cabin, baggage compartment, and wing pods, as needed. The 
usage of new high-speed, low-power processor boards in each data-sampling module (DSM) allows for efficient sampling and processing of collected GV data products throughout the full environmental regime in which the aircraft can operate. Access to, and recording of, outputs from the aircraft inertial navigation system (INS), global positioning system (GPS), and air data computer (ADC) are also provided via the GV data system.

- Data display and access: Current and planned capabilities of the onboard software utilities include the provision of real-time data displays, a System Query Language (SQL) database for the storage of low-rate (1 sample per second) data products, real-time data quality checking to provide for the flagging of bad data values, real-time Internet communications and data access both in flight and remotely from the ground, distribution and recording of imagery from the X-band weather avoidance radar mounted in the GV nose, and digital video camera display/image storage.

- Intercommunication system (ICS): The installed system provides eight stations in the cabin and one in the baggage compartment. Cabin stations provide users with the capability to talk not only to each other but also to the cockpit crew and outside of the GV using either the SATCOM systems or one of the VHF radios.

- State parameter and air motion sensing systems: For every mission, HIAPER is outfitted with a radome gust probe (three-dimensional winds) system, a research pitot-static system, and ambient pressure, temperature, and dewpoint sensors.

- Cabin equipment racks: The basic equipment rack designed and built by NCAR provides a standard 48.3 -cm (19 in.) rack mount interface for instrumentation and equipment. Each rack has dimensions of $56 \mathrm{~cm}$ wide, $67 \mathrm{~cm}$ deep, and $123 \mathrm{~cm}$ tall and accommodates a maximum capacity of $154 \mathrm{~kg}$ of equipment with a center of gravity (CG) approximately $74 \mathrm{~cm}$ above the floor attachment plane. Ceiling attachment points have also been installed in the aircraft to which racks can be secured in order to compensate for high-rackoverturning moments.

- SATCOM systems: Both Inmarsat and Iridium SATCOM systems have been installed on the GV. This combination of installed equipment provides investigators with nearly global coverage for voice and fax communications and data transmission, and the Inmarsat SATCOM system makes possible the transfer of data products to and from the aircraft at speeds of up to $128 \mathrm{~kb} \mathrm{~s}^{-1}$.

\section{DEVELOPMENT OF THE NEXT GENERA- TION OF AIRBORNE INSTRUMENTATION.}

The ability to fully capitalize on the research potential afforded by the GV requires that investigators adapt their desired payloads to the performance capabilities of the aircraft. Smaller, lighter, power-efficient, and perhaps autonomous (i.e., no in-flight operator required) sensors are becoming the rule rather than the exception and will enable GV scientists to assemble comprehensive payloads that provide all of the critical environmental measurements needed during proposed research missions. In order to facilitate the development of an initial suite of dedicated sensors for the aircraft, $\$ 12.5$ million of the total HIAPER project budget was set aside by NSF for the construction of GV instrumentation. NCAR and NSF turned to members of the environmental sciences community for input, guidance, and expertise during the process of determining how best to allocate and award these funds.

During a November 2002 workshop held at NCAR (more information available online at www.hiaper. ucar.edu/archive/02workshop/index.html), priorities for HIAPER environmental measurement needs were outlined by international representatives of universities, government laboratories, and private industry. Following the workshop, members of the HIAPER instrumentation subgroups and the HIAPER Advisory Committee (HAC) worked together to assemble a final document summarizing measurement priorities for the GV. This document was used by NSF to craft the solicitation for proposals for HIAPER instrumentation development. In the summary document released by the HAC (titled "HIAPER Instrumentation Priorities: A Report to the NSF from the HIAPER Advisory Committee" and available online at www. hiaper.ucar.edu/hac.html), each measurement was categorized as being standard (available on all GV flights), routine (available upon request), or research (innovative instrumentation provided on an as-needed basis and typically requiring a dedicated investigator for operation and support).

In August 2004, following the conduct of a formal instrumentation proposal solicitation and review process by NSF, NCAR and NSF announced the successful proposals. Instrument development awards were made to 14 principal investigators (PIs), and Table 3 provides information on the sensors selected, the PIs, and the PI institutions. Work to design and build these 14 new GV instruments is now well underway, and delivery of the sensors to UCAR/NCAR will take place from 2006 to 2009. Each of the instruments developed using HIAPER funds will be owned by UCAR and will be made available for priority usage on the GV. 


\begin{tabular}{|c|c|c|}
\hline Instrument & Principal investigator & Description \\
\hline Small ice detector (SID) probes & A. Heymsfield (UCAR/NCAR) & $\begin{array}{l}\text { Particle light scattering instrument for measuring } \\
\text { size distributions of particles in the } 1-70-\mu \mathrm{m} \text { size } \\
\text { range and for discriminating between ice crystals } \\
\text { and supercooled water droplets in mixed phase } \\
\text { clouds. }\end{array}$ \\
\hline $\begin{array}{l}\text { HIAPER Atmospheric Radiation } \\
\text { Package (HARP) }\end{array}$ & R. Shetter (UCAR/NCAR) & $\begin{array}{l}\text { Spectrally resolved actinic flux measurements } \\
\text { and spectroradiometric actinic flux and irradiance } \\
\text { measurements. }\end{array}$ \\
\hline Fast ozone instrument & T. Campos (UCAR/NCAR) & $\begin{array}{l}\text { Quantification of ozone mixing ratios at } 5 \mathrm{~Hz} \text { using } \\
\text { the method of chemiluminescent reaction of ozone } \\
\text { with nitric oxide. }\end{array}$ \\
\hline $\begin{array}{l}\text { Trace Organic Gas Analyzer } \\
\text { (TOGA) }\end{array}$ & E. Apel (UCAR/NCAR) & $\begin{array}{l}\text { In situ measurements of oxygenated volatile organic } \\
\text { compounds (OVOCs), nonmethane hydrocarbons } \\
\text { (NMHCs), and halocarbons. }\end{array}$ \\
\hline $\begin{array}{l}\text { HIAPER Advanced Whole Air } \\
\text { Sampler (AWAS) }\end{array}$ & E. Atlas (University of Miami) & $\begin{array}{l}\text { Collection of ambient air samples autonomously for } \\
\text { subsequent analysis of trace gas chemical and/or } \\
\text { isotopic composition. }\end{array}$ \\
\hline $\begin{array}{l}\text { Quantum cascade laser } \\
\text { spectrometer for HIAPER }\end{array}$ & S. Wofsy (Harvard University) & $\begin{array}{l}\text { Concentration data versus time for } \mathrm{CO}_{2}, \mathrm{CH}_{4} \text {, and } \\
\mathrm{CO}\left(\mathrm{N}_{2} \mathrm{O} \text { optional). }\right.\end{array}$ \\
\hline $\begin{array}{l}\text { Autonomous airborne ozone } \\
\text { photometer for the HIAPER aircraft }\end{array}$ & T. Rawlins (PSI, Inc.) & $\begin{array}{l}\text { Measurements of ozone mixing ratios versus time at } \\
\text { a data rate of I Hz. }\end{array}$ \\
\hline High spectral resolution lidar & $\begin{array}{l}\text { E. Eloranta (University of } \\
\text { Wisconsin-Madison) }\end{array}$ & $\begin{array}{l}\text { Calibrated vertical cross sections of cloud and } \\
\text { aerosol optical depth, backscatter cross section, and } \\
\text { depolarization. }\end{array}$ \\
\hline $\begin{array}{l}\text { GPS multistatic and occultation } \\
\text { instrument for HIAPER }\end{array}$ & J. Garrison (Purdue University) & $\begin{array}{l}\text { Measurements of water vapor distribution in the } \\
\text { troposphere, ocean surface roughness, and soil } \\
\text { moisture. }\end{array}$ \\
\hline $\begin{array}{l}\text { Vertical Cavity Surface Emitting } \\
\text { Laser (VCSEL) Hygrometer }\end{array}$ & M. Zondlo (Southwest Sciences) & $\begin{array}{l}\text { Measurements of water vapor concentration at a } \\
\text { minimum frequency of } 25 \mathrm{~Hz} \text { over the entire range } \\
\text { of the troposphere and lower stratosphere. }\end{array}$ \\
\hline $\begin{array}{l}\text { Time-of-Flight Aerosol Mass } \\
\text { Spectrometer (ToF-AMS) }\end{array}$ & $\begin{array}{l}\text { J. Jimenez (University of Colorado } \\
\text { at Boulder) }\end{array}$ & $\begin{array}{l}\text { Measurements of total PMI mass concentrations } \\
\text { for nonrefractory (NR) species, size-resolved } \\
\text { PMI composition for NR species, single particle } \\
\text { composition during selected portions of a flight, } \\
\text { light scattering signal intensity for particles above } \\
\sim 250 \mathrm{~nm} \text { correlated with mass spectral signal, and } \\
\text { surrogate nonsphericity. }\end{array}$ \\
\hline $\begin{array}{l}\text { Microwave Temperature Profiler } \\
\text { (MTP) }\end{array}$ & M. J. Mahoney (JPL/Caltech) & $\begin{array}{l}\text { Measurements of brightness temperature at three } \\
\text { frequencies between } 55.5 \text { and } 58.8 \mathrm{GHz} \text { to be used } \\
\text { to retrieve a temperature profile about the aircraft } \\
\text { flight altitude. }\end{array}$ \\
\hline $\begin{array}{l}\text { Chemical lonization Mass } \\
\text { Spectrometer (CIMS) }\end{array}$ & $\begin{array}{l}\text { G. Huey (Georgia Institute of } \\
\text { Technology) }\end{array}$ & $\begin{array}{l}\text { Measurements of nitric acid, pernitric acid, and } \\
\text { sulfur dioxide in standard CIMS (negative ion) mode, } \\
\text { and measurements of organics such as methanol, } \\
\text { acetaldehyde, acetonitrile, and acetone in CIMS } \\
\text { positive ion mode. }\end{array}$ \\
\hline $\begin{array}{l}\text { 2D-S (Stereo) and Cloud Particle } \\
\text { Imager (CPI) Probe }\end{array}$ & P. Lawson (SPEC, Inc.) & $\begin{array}{l}\text { 2D-S portion of probe to provide two different } \\
\text { (orthogonal) views of particles. CPI portion to } \\
\text { provide eight-bit (gray level) images of particles. }\end{array}$ \\
\hline
\end{tabular}

Additional critical instrumentation needs for HIAPER are also being met using some of the program's infrastructure funds. For example, a fuselage-mounted dropsonde deployment system and basic trace gas and particle-sampling inlets for the GV were developed by NCAR personnel using 
some of these funds and are now available for use on the aircraft.

\section{THE ROLE OF HIAPER IN ADDRESSING CRITICAL ENVIRONMENTAL ISSUES. An}

improved understanding of the global environment will be an important driver in decision-making processes that pertain to matters of environmental protection and economic sustainability. Areas of scientific inquiry that are of importance to society include 1) obtaining a better understanding of - and ability to predict-weather systems for the protection of life and property; 2) better understanding the dynamics of the Earth-climate system, including energy, water, and carbon cycles and their roles in climate forcing; 3 ) arriving at improved predictions of environmental change through an improved understanding of the production, evolution, transport, and radiative properties of trace chemical species, aerosols, and cloud particles, and the interactions and feedbacks of energy between the atmosphere and underlying oceans, land surface, and sea ice; and 4) gaining an improved understanding of exchanges between the tropospheric and stratospheric regions of the atmosphere, including the role of organized convective systems. HIAPER is a unique platform that will enable scientists to address these problems, and the research contributions that will be possible using this aircraft can be summarized in the context of expected contributions to weather and water cycle research, atmospheric chemistry and climate system forcing, and the monitoring of biosphere structure and productivity.

Weather and water cycle research. Recent winter flooding events on the U.S. west coast have led to loss of life and extensive property damage from debris flow and flash flooding. These events underscore the need for better medium-range precipitation forecasting (up to 5 days) from global-scale models, especially quantitative precipitation forecasts of extratropical cyclones and landfalling fronts and squall lines. Improved short-term numerical model forecasts require an improved understanding of the physics of these storm systems, including frontogenesis, frontolysis, and storm structure, and a better understanding of storm momentum, heat, and moisture transport mechanisms. Observations of these storm systems, particularly days before landfall, require the utilization of an aircraft with HIAPER's capabilities, that is, long-range flight characteristics, the capacity to carry modern in situ and remote sensors to a variety of altitudes, and high air speeds (relative to the flight speeds of existing turboprop platforms) necessary to make mesoscale observations in a synoptic, or nearsimultaneous, time frame.

Our limited understanding of the fundamental cloud processes involved in atmospheric precipitation formation impedes our progress in advancing resolvable-scale cumulus processes in global weather forecast models (Chen and Avissar 1994). The generation and evolution of upper-tropospheric potential vorticity anomalies play a strong role in the formation and evolution of large-scale weather systems. Observations to be made with HIAPER will enable research to be conducted on tropopause folds, stratospheric intrusions, dry-slot formation in midlatitude storm systems, and a wide range of interacting and related gravity wave processes. Such observations require that measurements be made over large $(1000 \mathrm{~km})$ scales and at altitudes above the tropopause at midlatitudes. When equipped with suitable cloud physics sensors and remote sensing devices for the detection of in-cloud and clear-air motions, HIAPER will enable investigators to obtain critical observations needed to better understand atmospheric dynamics and the water cycle and to better parameterize these processes in global weather prediction models.

Improved measurements of global water vapor require a mix of satellite sensors, aircraft observations, and ground-based measurements. An aircraft like the GV will be able to provide accurate in situ validation datasets for space- and ground-based systems. New lidar water vapor observing systems (still to be developed) that can be deployed on HIAPER will allow for the synoptic-scale coverage of water vapor measurements over land or ocean surfaces, as well as the collection of high-resolution profiles covering full daytime or nighttime cycles and full tropospheric water vapor profiles. Such measurements will be essential for validating satellite remote sensors and, subsequently, for improving global model forecasts of precipitation (Lau et al. 1996).

Atmospheric chemistry and climate forcing. The discovery of key chemical, photochemical, and microphysical processes in the atmosphere has often resulted from the analysis of data gathered during airborne campaigns. Large instrumented payloads providing simultaneous measurements of several compounds and physical parameters in different atmospheric environments have been used to characterize key chemical or microphysical transformations occurring within specific air parcels.

After two decades during which the scientific community has "taken the Earth apart" to study, 
for example, individual chemical and microphysical processes in the atmosphere, it appears important today to "put the Earth back together" and analyze its complex functioning in order to better predict its evolution. Thus, atmospheric research is increasingly defined by a systems approach, in which atmospheric processes are investigated as part of an interactive system that includes physical, chemical, biological, and human interactions between the atmosphere, ocean, and continental biosphere. An aircraft with the capabilities of HIAPER will be an exceptionally important tool for addressing important Earth system issues in which atmospheric chemistry plays an important role. The GV will enable investigators to collect observations that cannot be obtained using other types of platforms (including spacecraft).

Among the important issues on the agenda of the scientific community are complex questions related to chemistry-climate interactions, the oxidizing power of the atmosphere, and air quality and chemical weather (Brasseur et al. 2003). Issues that are key to understanding the fate of the Earth system include the perturbations in the carbon and nitrogen cycles, the direct and indirect effects of aerosols on climate, changes in the global stratospheric and tropospheric budgets of ozone, atmospheric radicals, hydrocarbons, and halogenated compounds, and the mechanisms that control global and regional air pollution, including surface emissions and deposition as well as long-range transport. In the coming years, scientists will address chemical aspects of systemic issues, including spatial patterns of climate forcing, the oxidizing power of the atmosphere, ozone effects on climate, the formation of organic aerosols, and aerosol radiative and hydrologic impacts. Some examples of the challenging questions needing to be addressed fall into the following broad categories.

INTERACTIONS BETWEEN DYNAMICS, CHEMISTRY, AND RADIATION IN THE UPPER TROPOSPHERE-LOWER STRATOSPHERE. Radiative forcing in the climate system depends strongly on the concentration of radiatively important compounds in the upper troposphere and lower stratosphere, including greenhouse gases, ozone, and aerosols. The region close to the tropopause, which can be reached by high-altitude aircraft such as HIAPER, exhibits a complex interplay between dynamics, transport, radiation, chemistry, and microphysics. Strong vertical gradients are observed in the mixing ratio of many trace constituents, including water vapor and ozone. This results in large part from the fact that the production and destruction mechanisms for many species are very different in the troposphere and stratosphere. Processes characterizing transport between these two atmospheric regions occur on a multitude of scales including global, synoptic, and subsynoptic. Of particular interest is the behavior of water vapor and various chemical compounds in the so-called tropical tropopause layer (TTL).

THE TROPICAL REACTOR. The tropical region is of great geophysical and climatic importance. It strongly affects the carbon cycle through exchanges of $\mathrm{CO}_{2}$ between the atmosphere, ocean, and continental biosphere. Atmospheric chemistry is particularly active in this region, which receives large quantities of solar energy. Vertical exchanges by convection can occur extremely quickly, and signals related to surface processes can rapidly reach the tropical tropopause layer. Lightning is also frequent in vigorous storms, and intense precipitation removes soluble species from the atmosphere. Massive deforestation and land-use changes with associated biomass burning have profoundly affected the tropical region.

Atmospheric transport. Perhaps the largest uncertainties in chemical transport models are those associated with the formulation of subgrid transport. Large-scale advection is usually well simulated, but transport associated with smaller-scale features, and specifically vertical exchange, is not yet well quantified. Furthermore, parameterization of such transport is often approximate. Observational data are needed and should focus on obtaining information about fast exchanges within frontal systems and convective storms and on exchanges between atmospheric layers and the surface.

Projects designed to address some of the questions outlined in the preceding three sections will require the use of multiple aircraft [e.g., HIAPER, Deutsches Zentrum für Luft-und Raumfahrt (DLR) HighAltitude and Long Range Research Aircraft (HALO), the NASA WB-57F, the NSF/NCAR C-130, etc.], and even multiple types of platforms (spacecraft, vertical profilers, ground-based systems, ships). HIAPER should, therefore, be regarded as one important platform that will complement others. Satellites provide the broad coverage needed to partially validate global models, but such systems provide little vertical profile information. It must also be recognized that the ultimate scientific success of the GV will depend not only on the development of quality instrumentation for use on the aircraft but also on the concurrent development of suitable data assimilation techniques and complex models. 
Monitoring the structure and productivity of the biosphere. Data from imaging and profiling instruments deployed on airborne and satellite platforms are essential inputs to climate and ecosystem models (NRC 1998, 2004; Running et al. 2004). Because of inaccurate parameterizations, however, current process models produce wide disagreement in the location, types, and timing of ecosystem change when predicting future responses to climate change (NRC 2001, 2004). There is an unmet need to develop, test, and validate new remote sensing technologies to acquire the data needed for these models and to produce more reliable predictions. The suborbital HIAPER platform with its extended flight duration capabilities will allow for the deployment of observational systems at geographical scales that will meet this need and will enable investigators to pursue measurement scenarios that will contribute significantly to the systematic study of the Earth system. Specifically, the simultaneous acquisition of airborne imaging spectrometer and lidar data from HIAPER will potentially transform current Earth-observing measurement and monitoring capabilities by providing the types of data that are needed to define the state and condition of ecosystems at spatial resolutions that are not possible using ground or satellite sensors.

Imaging spectrometry and lidar are state-of-theart technologies that, when employed together, provide estimates of both biogeochemical properties and the three-dimensional structure of the land surface. Such observations are needed in order to improve predictions of ecosystem feedbacks to climate change. The type of coordinated spectrometer and lidar measurements needed are not yet available from spaceborne platforms, and the flight duration, range, and altitude capabilities of HIAPER (see Table 1) and the ability to perform variable mission scenarios with this platform (e.g., by varying the time of day, orientation, altitude, and repeat period of flights) are essential for advancing scientific understanding of the terrestrial environment.

Climate and land-use changes are rapidly altering the structure, function, and biological diversity of the terrestrial environment in ways that are currently unpredictable. Great uncertainties exist in understanding ecosystem feedbacks through the regulation of carbon, water, and energy exchanges. Spectroscopy is currently used to measure and quantify a wide range of biogeochemical features that are of importance for Earth observation, including vegetation pigment composition and content (Fuentes et al. 2001; Jacquemoud et al. 1996), canopy water content (Gao 1996; Ustin et al. 1998), and dry plant litter and/or wood
(Asner 1998; Fourty et al. 1996). Additionally, soil surface properties like organic matter, clay type, and mineral content (Clark 1999; Huete 2004), as well as atmospheric water vapor (Ogunjemiyo et al. 2002) and ice clouds (Gao and Li 2000), can be quantified and mapped using spectroscopy. HIAPER will fill a critical need by enabling investigators to obtain spectroscopic measurements of such biogeochemical properties from a stable, upper-tropospheric platform. Such measurements will be essential for testing and modeling climate change and, because of the temporal and regional scales of the data collected, will provide an important bridge between ground- and satellite-based observations.

One of the largest uncertainties in understanding the global carbon budget is knowledge of the amount, variability, and dynamics of stored biomass in global ecosystems. Airborne lidar technology can produce accurate three-dimensional (3D) maps of canopy structure, which are then used to characterize spatial variation in forest structure and biomass (Lefsky et al. 1999,2002 ) and to estimate fuel loading for wildfire hazard assessment and atmospheric emissions (Riaño et al. 2003). A well-calibrated, full-waveform, or small-footprint lidar is needed to obtain measurements that will help to reduce uncertainties in carbon storage information (Gardner et al. 2003; Weishampel et al. 2000). Limitations on lidar systems deployed in space make airborne measurements that cover a wide range of ecosystem conditions essential for reducing this uncertainty. The deployment of such sensors on the high-altitude, long-range HIAPER platform will enable Earth science investigators to obtain critical observations of global ecosystems over a wide range of environmental conditions and sites.

\section{THE START OF GV RESEARCH OPERA-}

TIONS. With the support of NSF and the scientific community, NCAR elected to take a measured approach to the start of GV operations and initiated a gradual spinup to full-scale research missions. From the fall through early winter of 2005, HIAPER was outfitted and deployed from its local base of operations (Jefferson County Airport in Broomfield, Colorado) in support of a series of progressive science missions.

The primary objectives established for these missions were as follows:

- Providing a significant time period during which NCAR personnel could become thoroughly familiar with the operation and performance capabilities of the GV and with the operation of the various infrastructure systems on the aircraft; 
- permitting NCAR staff to support the gradual development of fundamental (standard) instrumentation for the aircraft;

- ensuring a suitable time period for NCAR personnel to work through payload certification processes and issues;

- showcasing the altitude and endurance capabilities of the GV while demonstrating the new data collection, display, satellite communications, and data transfer capabilities of the aircraft infrastructure systems; and

- providing members of the scientific community with a valuable opportunity to perform initial, well-defined scientific missions with the GV.

Following the conclusion of the progressive science missions, the GV became available to the geosciences community for full-scale research missions support. The first large-scale observational program to be supported by HIAPER - the Terrain-Induced Rotor Experiment (T-REX; see Grubišič et al. 2004; more information is available online at www.joss.ucar.edu/trex) - took place from March to April 2006. Members of the scientific community interested in using the GV for the conduct of research programs can request HIAPER support using the existing NSF deployment pool and observing facility allocation process. Information on available NSF lower-atmospheric observing facilities and facility request procedures is available online at www.eol.ucar. edu/dir_off/OFAP/info/UserGuide.pdf.

ACKNOWLEDGMENTS. The authors wish to thank all of the participants in the November 2002 NSF-led Community Workshop on Instrumentation for HIAPER, the HIAPER instrumentation subgroups, and the members of the HIAPER Advisory Committee for their input and guidance during discussions of HIAPER measurement priorities and instrumentation development strategies. An important product of the workshop was essays by Robert Serafin (NCAR), Azadeh Tabazadeh (Stanford University), and David Fahey (NOAA) on the value of HIAPER to various research disciplines. We thank them for their timely and important contributions, which can be found on the HIAPER Web site (www.hiaper.ucar.edu). The authors also wish to thank Richard Friesen and Mark Lord of NCAR for their work in preparing information and figures regarding the performance of the GV and David Fahey of NOAA for his contribution of Fig. 2. Richard Friesen, Julie Haggerty, Donald Lenschow, and William "Al" Cooper of NCAR and three anonymous reviewers provided helpful comments on earlier drafts of this manuscript. Finally, we thank Gulfstream Aerospace Corporation and Lockheed Martin for their assistance in preparing Fig. 6.

\section{REFERENCES}

Asner, G. P., 1998: Biophysical and biochemical sources of variability in canopy reflectance. Remote Sens. Environ., 64, 234-253.

Brasseur, G. P., R. G. Prinn, and A. P. Pszenney, Eds., 2003: Atmospheric Chemistry in a Changing World. Springer-Verlag, $330 \mathrm{pp}$.

Chen, F., and R. Avissar, 1994: Impact of land-surface moisture variability on local shallow convective cumulus and precipitation in large-scale models. J. Appl. Meteor., 33, 1382-1401.

Clark, R. N., 1999: Spectroscopy of rocks and minerals, and principles of spectroscopy. Remote Sensing for the Earth Sciences: Manual of Remote Sensing, Vol. 3, ASPRS, A. N. Rencz, Ed., John Wiley \& Sons, 3-58.

Cooper, W. A., W. B. Johnson, J. E. Ragni, G. L. Summers, and M. N. Zrubek, 1989: Scientific justification and development plan for a mid-sized jet research aircraft. NCAR Tech. Note NCAR/TN-337+EDD, $59 \mathrm{pp}$.

Fourty, T. H., F. Baret, S. Jacquemoud, G. Schmuck, and J. Verdebout, 1996: Optical properties of dry plant leaves with explicit description of their biochemical composition: Direct and inverse problems. Remote Sens. Environ., 56, 104-117.

Fuentes, D. A., J. A. Gamon, H. L. Qiu, D. A. Sims, and D. A. Roberts, 2001: Mapping Canadian boreal forest vegetation using pigment and water absorption features derived from the AVIRIS sensor. J. Geophys. Res., 106, 33 565-33 577.

Gao, B. C., 1996: NDWI-A normalized difference water index for remote sensing of vegetation liquid water from space. Remote Sens. Environ., 58, 257-266.

—, and R.-R. Li, 2000: Quantitative improvement in the estimates of NDVI values from remotely sensed data by correcting thin cirrus scattering effects. Remote Sens. Environ., 74, 494-502.

Gardner, J. V., T. Warner, D. M. Nellis, and T. Brandtberg, 2003: Virtual reality technology for Lidar data analysis. Proc. SPIE, 5097, 48-57.

Grubišić, V., J. D. Doyle, J. Kuettner, G. S. Poulos, and C. D. Whiteman, 2004: Terrain-induced Rotor Experiment (T-REX). Scientific overview document and experiment design, $72 \mathrm{pp}$. [Available online at www.joss.ucar.edu/trex.]

Hildebrand, P. H. and J. McCarthy, 1983: The NCAR research aviation workshop, 18-19 February 1982, Boulder, Colorado. Meeting Review. Bull. Amer. Meteor. Soc., 64, 481-490.

Huete, A., 2004: Remote sensing of soils and soil processes. Remote Sensing for Natural Resource Management and Environmental Monitoring, Manual of 
Remote Sensing, Vol. 3, ASPRS, S. L. Ustin, Ed., John Wiley and Sons, 3-52.

Jacquemoud S., S. L. Ustin, J. Verdebout, G. Schmuck, G. Andreoli, and B. Hosgood, 1996: Estimating leaf biochemistry using the PROSPECT leaf optical properties model. Remote Sens. Environ., 56, 194-202.

Johnson, W. B., and W. A. Cooper, 1989: Meeting review: The second NCAR research aircraft fleet workshop, 15-16 April 1987, Boulder, Colorado. NCAR Tech. Note NCAR/TN-332+PROC, 84 pp.

Lau, K.-M., Y. Sud, and J. H. Kim, 1996: Intercomparison of hydrologic processes in AMIP GCMs. Bull. Amer. Meteor. Soc., 77, 2209-2227.

Lefsky, M. A., W. B. Cohen, S. A. Acker, G. G. Parker, T. A. Spies, and D. Harding, 1999: Lidar remote sensing of the canopy structure and biophysical properties of Douglas-fir western hemlock forests. Remote Sens. Environ., 70, 339-361.

— — — G. C. Parker, and D. J. Harding, 2002: Lidar remote sensing for ecosystem studies. BioScience, 52, 19-30.

NRC, 1998: Global Environmental Change: Research Pathways for the Next Decade. National Academy Press, 603 pp.

—, 2001: Grand Challenges in Environmental Sciences. National Academy Press, 96 pp.
—, 2004: Implementing Climate and Global Change Research: A Review of the Final U.S. Climate Change Science Program Strategic Plan. National Academy Press, 152 pp.

Ogunjemiyo, S., D. A. Roberts, K. Keightley, S. L. Ustin, T. Hinckley, and B. Lamb, 2002: Evaluating the relationship between AVIRIS water vapor and forested land cover. J. Geophys. Res., 107D, 4719, doi.10:1029/2001JD001194.

Riaño, D., E. Meier, B. Allgöwer, E. Chuvieco, and S. L. Ustin, 2003: Modeling airborne laser scanning data for the spatial generation of critical forest parameters in fire behavior modeling. Remote Sens. Environ., 86, 177-186.

Running, S. W., R. R. Nemani, F. A. Heinsch, M. Zhao, M. Reeves, and H. Hashimoto, 2004: A continuous satellite-derived measure of global terrestrial primary production. BioScience, 54, 547-560.

Ustin, S. L., D. A. Roberts, S. Jacquemoud, J. Pinzón, M. Gardner, G. J. Scheer, C. M. Castaneda, and A. Palacios, 1998: Estimating canopy water content of chaparral shrubs using optical methods. Remote Sens. Environ., 65, 280-291.

Weishampel, J. F., J. B. Blair, R. G. Knox, R. Dubayah, and D. B. Clark, 2000: Volumetric lidar return patterns from an old-growth tropical rainforest canopy. Int. J. Remote Sens., 21, 409-415. 